\title{
VORONOVSKAJA'S THEOREM FOR SCHOENBERG OPERATOR
}

\author{
GANCHO TACHEV
}

Abstract. In this paper we represent new quantitative variants of Voronovskaja's Theorem for Schoenberg variation-diminishing spline operator. We estimate the rate of uniform convergence for $f \in C^{2}[0,1]$ and generalize the results obtained earlier by Goodman, Lee, Sharma, Gonska etc.

Mathematics subject classification (2010): 41A10, 41A15, 41A17, 41A25, 41A17, 41A25, 41A36. mation.

Keywords and phrases: Schoenberg-spline operator, Voronovskaja-type theorem, Degree of approxi-

\section{REFERENCES}

[1] L. Beutel, H. H. Gonska, D. Kacso, G. TACHEV, On variation-diminishing Schoenberg operators: new quantitative statements, Multivariate Approximation and Interpoltaion with Applications (ed. by M. Gasca), Monogr. Academia Ciencas de Zaragoza, 20 (2002), 9-58.

[2] L. Beutel, H. H. Gonska, D. Kacso, G. Tachev, On the Second Moments of VariationDiminishing Splines, J. of Concr. and Appl. Math., 2, 1 (2004), 91-117.

[3] P. J. DAVIS, Interpolation and Approximation, Blaisdell, New York, (1963).

[4] T. N. T. Goodman, S. L. LeE And A. Sharma, Asymptotic formula for the Bernstein-Schoenberg Operator, Approx. Theory and its Appl., 4 (1988), 67-86.

[5] T. N. T. Goodman And A. Sharma, A Property of Bernstein-Schoenberg Operators, Proc. Edinburgh Math. Soc., 28 (1985), 333-340.

[6] H. Gonska, P. Pitul And I. RasA, On Peano's form of the Taylor remainder, Voronovskaja's theorem and the commutator of positive linear operators, in: "Numerical Analysis and Approximation Theory" (Proceedings of the Int. Conf. 2006 in Cluj-Napoca, (2006), 55-80.

[7] H. Gonska, On the degree of Approximation in Voronovskaja's theorem, Studia Univ. Babes-Bolyai, Mathematica, vol., LII, 3 (2007), 103-115.

[8] A. Lupas, Doctoral Dissertation, Universitatea Babes-Bolyai, Cluj-Napoca, (1975).

[9] M. Marsden And I. Schoenberg, On Variation-Diminishing Spline Approximation Methods, Mathematica 8 (31), 1 (1966), 61-82.

[10] M. MARSDEn, An identity for spline functions with applications to variation-diminishing spline approximation, J. of Approx. Th., 3 (1970), 7-49.

[11] M. MARSDEN, A Voronovskaja's theorem for variation-diminishing spline approximation, Can. J. Math., vol. 38, 5 (1986), 1081-1093.

[12] I. J. Schoenberg, On spline functions, in: Inequalities, Academic Press, New York, (1967), 255291.

[13] E. Voronovs KaJA, Determination de la forme asymptotique d'approximation des fonctions par les polynomes de M. Bernstein, Dokl. Akad. Nauk SSSR, 4 (1932), 86-92. 